\title{
PENGARUH MODEL PEMBELAJARAN COOPERATIVE SCRIPT DENGAN MEDIA KARTU GAMBAR TERHADAP MINAT DAN HASIL BELAJAR SISWA PADA MATERI PERKEMBANGAN MODEL ATOM
}

\author{
Ayu Rahmi ${ }^{1^{*}}$, Henni Fitriani ${ }^{2}$, dan Nurul Muna ${ }^{3}$ \\ 1,2 Dosen Program Studi Pendidikan Kimia, Universitas Malikussaleh \\ ${ }^{3}$ Mahasiswa Program Studi Pendidikan Kimia, Universitas Malikussaleh \\ Jln. Cot Teungku Nie, Kec. Muara Batu, Kab. Aceh Utara \\ *Email: ayu.rahmi@unimal.ac.id
}

\begin{abstract}
Abstrak
Penelitian ini bertujuan untuk mengetahui pengaruh model Cooperative Script dengan media kartu gambar terhadap minat dan hasil belajar siswa pada materi perkembangan model atom kelas X IPA. Jenis penelitian yang digunakan adalah pre experimental design dengan desain one group pretestposttest design. Penelitian ini dilakukan di SMA Negeri 1 Peusangan. Populasi dalam penelitian ini adalah seluruh siswa kelas X IPA SMA Negeri 1 Peusangan. Pengambilan sampel menggunakan teknik purposive sampling sehingga yang menjadi sampel penelitiannya adalah siswa kelas X IPA 2 dengan jumlah 24 siswa. Teknik pengumpulan data menggunakan tes yang terdiri dari soal pretest, posttest, dan angket. Berdasarkan hasil penelitian, rata-rata hasil pretest siswa sebesar 35,63 dan rata-rata hasil posttest siswa sebesar 78,33. Data pretest dan posttest diuji normalitas dengan hasil < 0,05 yang menyatakan bahwa data tidak berdistribusi normal, kemudian dilanjutkan dengan uji hipotesis melalui teknik Wilcoxon dengan hasil < 0,05 yang membuktikan bahwa Ha diterima. Sedangkan penilaian angket minat belajar diperoleh hasil persentase rata-rata minat belajar siswa yaitu 73,33\% dengan kategori baik. Dengan demikian dapat disimpulkan bahwa model Cooperative Script dengan media kartu gambar mempengaruhi minat dan hasil belajar siswa pada materi perkembangan model atom kelas X IPA SMA Negeri 1 Peusangan.
\end{abstract}

Kata Kunci: Cooperative Script, Kartu Gambar, Minat, Hasil Belajar

\begin{abstract}
This study aims to determine the effect of the Cooperative Script model with picture card media on students' interest and learning outcomes in the development of the atomic model in class X IPA. This type of research is pre-experimental design with one group pretest-posttest design. This research was conducted at SMA Negeri 1 Peusangan. The population in this study were all students of class X IPA SMA Negeri 1 Peusangan. The sample was taken by using purposive sampling technique so that the sample of the research was 24 students of class X IPA 2. The data collection technique used a test consisting of pretest, posttest, and questionnaire questions. Based on the results of the study, the average student pretest results were 35.63 and the average student posttest results were 78.33 . The pretest and posttest data were tested for normality with a result $<0.05$ which stated that the data were not normally distributed, then continued with hypothesis testing through the Wilcoxon technique with a result $<0.05$ which proved that Ha was accepted. While the assessment of the interest in learning questionnaire obtained the average percentage of student interest in learning, namely $73.33 \%$ with a good category. Thus it can be concluded that the Cooperative Script model with picture card media affects student interest and learning outcomes in the development of atomic model class X IPA SMA Negeri 1 Peusangan.
\end{abstract}

Keywords: Cooperative Script, Picture Card, Interest, Learning Outcomes

KATALIS Jurnal Penelitian Kimia dan Pendidikan Kimia

Vol. 4, No. 1, Juni 2021 


\section{PENDAHULUAN}

Pelajaran kimia merupakan pelajaran yang masih dianggap sulit oleh siswa dikarenakan kimia banyak materi yang berisi konsep-konsep yang abstrak dan bersifat hafalan. Salah satu materi kimia yang bersifat abstrak adalah perkembangan model atom. Materi perkembangan model atom terdiri dari beberapa pembahasan yaitu partikel penyusun atom, nomor atom dan nomor massa, serta perkembangan model atom. Dari beberapa pembahasan tersebut, kebanyakan siswa mengalami kesulitan untuk mengingat bagaimana cara menentukan partikel penyusun atom dalam suatu unsur dan bentuk-bentuk model atom yang ditemukan oleh para ahli.

Berdasarkan hasil observasi dan wawancara dengan guru mata pelajaran kimia di kelas X IPA SMA Negeri 1 Peusangan diperoleh informasi bahwa masih banyak siswa yang belum mencapai hasil yang memuaskan pada materi perkembangan model atom. Hal ini dibuktikan dengan nilai ulangan harian siswa kelas X tahun ajaran 2018/2019 masih rendah atau sedikit lebih tinggi dengan nilai KKM yaitu sebesar 70 . Banyaknya siswa yang hasil belajarnya kurang memuaskan pada pembahasan perkembangan model atom dikarenakan pembelajaran masih berpusat pada guru. Guru menerangkan pembelajaran dan siswa hanya mendengarkan dan mencatat materi sehingga siswa tidak terlatih kemampuan memahami dan mengingat dalam jangka waktu yang relatif lama. Selain itu, minat belajar siswa kurang dikarenakan suasana pembelajaran yang bersifat monoton, tidak ada interaksi antar siswa bahkan mereka bekerja secara individu terus menerus. Oleh karena itu seorang pendidik harus mampu merancang suasana pembelajaran yang menyenangkan dan mengikutsertakan seluruh peserta didik untuk saling berinteraksi supaya mereka dapat bertukar ide atau pendapat melalui jalannya diskusi. Misalnya, dengan menggunakan model pembelajaran yang dapat memicu keaktifan siswa.

Satu model pembelajaran yang bisa membantu meningkatkan interaksi antar siswa sehingga bisa melatih kemampuan mereka dan semangat mengikuti pembelajaran yaitu Cooperative Script. Model Cooperative Script adalah model yang mampu meningkatkan daya ingat siswa karena bekerja berpasangan dan bergantian secara lisan dalam mengikhtisarkan bagian-bagian materi yang dipelajari (Slavin dalam Indrawati, 2016:402).

Kelebihan model Cooperative Script salah satunya adalah siswa bisa berperan aktif dalam kegiatan belajar mengajar karena setiap orang yang ada di dalam kelas mendapat peran sebagai pembicara dan pendengar. Sedangkan kekurangan model pembelajaran ini yaitu hanya dilakukan oleh dua orang dalam satu kelompok yang menyebabkan koreksi hanya terbatas pada dua pemeran itu. Walau demikian, pendidik harus mampu mengorganisir situasi dan kondisi di dalam kelas supaya kegiatan pembelajaran tetap berjalan dengan baik (Budiyanto, 2016:37).

Penggunaan model pembelajaran akan lebih maksimal hasilnya apabila dikolaborasikan dengan media pembelajaran yang tepat. Salah satu media yang cocok dengan karakteristik materi perkembangan model atom adalah kartu gambar. Media ini merupakan suatu media grafis yang dapat digunakan untuk menarik perhatian, memperjelas materi pelajaran, dan mengilustrasikan fakta atau konsep yang gampang terlupakan apabila hanya dilakukan melalui penjelasan verbal atau tulisan. Media ini terbuat dari kartu dan memiliki ukuran tertentu. Setiap kartu berisi gambar yang ditempelkan guntingan gambar dari buku atau sumber belajar lainnya. Media kartu gambar bertujuan agar siswa tertarik dan mudah mengenal atau mengingat gambaran suatu objek dalam materi pelajaran yang sulit diingat seperti materi perkembangan model atom (Djamarah dalam Sandyasa, 2016:15). 
Dengan adanya media kartu gambar, siswa tidak lagi menghayal untuk membayangkan bagaimanakah bentuk model-model atom yang ditemukan oleh para ahli. Hal ini akan sangat membantu siswa dalam mengingat model- model atom dan partikel penyusun atom.

Berdasarkan uraian di atas, peneliti melakukan penelitian untuk mengetahui pengaruh penggunaan model pembelajaran Cooperative Script dengan media kartu gambar terhadap minat dan hasil belajar siswa pada materi Perkembangan Model Atom Kelas X IPA SMA Negeri 1 Peusangan. Hasil belajar yang menjadi fokus pada penelitian ini merupakan hasil belajar kognitif siswa.

\section{METODOLOGI PENELITIAN}

Penelitian ini dilaksanakan di SMA Negeri 1 Peusangan pada tanggal 17 Oktober sampai dengan 24 Oktober tahun ajaran 2019/2020. Populasi dalam penelitian ini adalah seluruh siswa kelas $X$ IPA SMAN 1 Peusangan Kabupaten Bireuen yang terdiri dari tiga kelas dengan jumlah siswa 72 orang, yaitu kelas X IPA 1 sebanyak 24 siswa, X IPA 2 sebanyak 24 siswa, dan X IPA 3 yang berjumlah 24 siswa. Sampel dalam penelitian ini adalah kelas $\mathrm{X}$ IPA 2 yang dipilih dengan menggunakan teknik Purposive Sampling. Instrumen yang digunakan dalam penelitian ini berupa tes dan angket. Tes terdiri atas pretest dan posttest. Soal pretest digunakan untuk mengukur sejauhmana penguasaan materi yang dimiliki siswa sebelum dilakukan penelitian, sedangkan soal posttest digunakan setelah kegiatan penelitian dilakukan. Adapun soal-soal tersebut harus di uji terlebih dahulu agar dapat dikategorikan sebagai instrumen yang baik dan layak untuk digunakan dalam penelitian. Uji yang dilakukan terdiri atas uji validitas, reliabilitas, tingkat kesukaran, dan daya pembeda. Penilaian hasil belajar yang diperoleh dari data pretest dan posttest diolah menggunakan rumus sebagai berikut.

$$
\text { Nilai siswa }=\frac{\text { Skor yang diperoleh }}{\text { Skor total }} \times 100
$$

Langkah selanjutnya adalah penggunaan angket. Angket digunakan untuk mengukur minat belajar siswa terhadap materi perkembangan model atom. Adapun rumus yang digunakan untuk mengukur minat adalah sebagai berikut.

$$
P=\frac{F}{N} \times 100
$$

dimana:

$\mathrm{P}=$ Persentase minat belajar siswa

$\mathrm{F}=$ Frekuensi yang sedang dicari persentasenya

$\mathrm{N}=$ Jumlah skor maksimum

(Sudijono dalam Fahni, 2014:38)

Kriteria minat belajar siswa dapat dilihat pada tabel berikut.

Tabel 1. Persentase Skor Minat Belajar Siswa

\begin{tabular}{|l|l|}
\hline \multicolumn{1}{|c|}{$\begin{array}{c}\text { Persentase Skor } \\
\text { Minat }\end{array}$} & \multicolumn{1}{|c|}{ Kriteria } \\
\hline $0-50 \%$ & Kurang \\
\hline $60-69 \%$ & Cukup \\
\hline $70-79 \%$ & Baik \\
\hline $80-100 \%$ & Sangat Baik \\
\hline
\end{tabular}

Sumber: Aritonang, (2008:15)

Setelah mendapat data-data terkait dengan hasil belajar kognitif dan minat siswa terhadap materi perkembangan model atom, hal terakhir yang dilakukan adalah melakukan uji hipotesis. Melalui uji inilah ditentukan apakah ada atau tidak pengaruh penggunaan model Cooperative Script dengan media kartu gambar terhadap minat dan hasil belajar siswa pada materi perkembangan model atom di kelas X IPA 2 SMA Negeri 1 Peusangan.

\section{HASIL DAN PEMBAHASAN}

Sebelum proses pembelajaran dengan menggunakan model Cooperative Script dengan media kartu gambar dimulai, dilakukan pretest yang bertujuan untuk mengetahui pengetahuan awal siswa pada 
materi perkembangan model atom. Kemudian, setelah proses pembelajaran selesai dilakukan posttest.

\section{Hasil Belajar}

Berdasarkan hasil penelitian dan analisis data dari jawaban pretest siswa yang terdiri atas 20 soal pilihan ganda, maka diperoleh jumlah jawaban benar terendah yaitu 6 dengan nilai 30, dan jumlah jawaban benar tertinggi yaitu 9 dengan nilai 45 .

Berdasarkan hasil penelitian dan analisis data dari jawaban posttest siswa yang terdiri atas 20 soal pilihan ganda, maka diperoleh jumlah jawaban benar terendah yaitu 11 dengan nilai 55 , dan jumlah jawaban benar tertinggi yaitu 18 dengan nilai 90 .

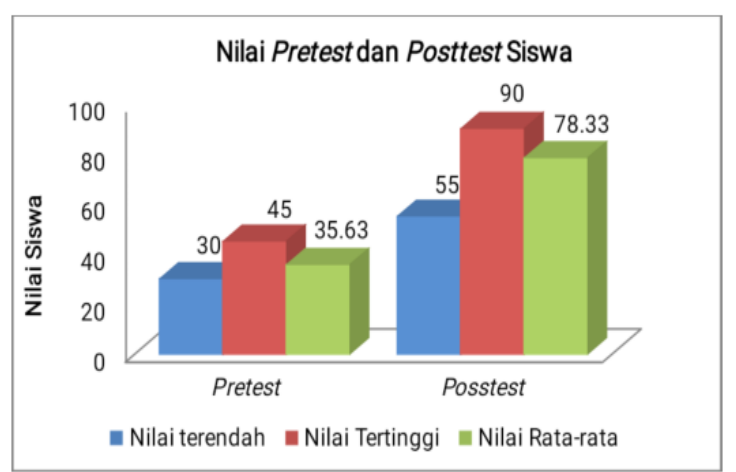

Gambar 1. Diagram Nilai Pretest dan Posttest Siswa

Berdasarkan nilai tersebut menunjukkan bahwa terdapat perbedaan hasil data pretest (sebelum diberi perlakuan) dan data posttest (setelah diberi perlakuan). Setelah data-data tersebut diperoleh, maka data tersebut harus diuji normalitasnya terlebih dahulu untuk mengetahui apakah data tersebut terdistribusi normal atau tidak. Uji normalitas menggunakan teknik shapiro wilk dikarenakan sampel yang diteliti $<50$ yaitu 24 siswa. Setelah diuji dengan teknik ini maka diperoleh hasil pretest yaitu $0,00<0,05$ dan posttest $0,02<0,05$. Hal ini menunjukkan bahwa data pretest dan posttest tidak terdistribusi normal. Apabila kedua data tidak terdistribusi normal maka digunakan uji nonparametrik yaitu wilcoxon signed ranktest. Jenis uji ini diterapkan untuk menganalisis penelitian pre-post. Uji beda diterapkan untuk menilai perlakuan (treatment) tertentu pada satu subjek yang sama pada dua periode pengamatan yang berbeda (Saidah dan Winda, 2018:98). Berdasarkan hasil uji tersebut, diperoleh Sig. (2-tailed) $<0,05$ yaitu $0,00<0,05$. Hal itu menjelaskan hipotesis diterima. Sehingga, model Cooperative Script dengan media kartu gambar mempengaruhi hasil belajar kognitif siswa.

\section{Minat}

Angket dibagikan pada siswa untuk mengukur minat belajarnya. Pada angket tersebut terdapat 10 pernyataan. Setiap pernyataan terdapat beberapa pilihan yaitu SS (sangat setuju) skor 4, S (setuju) skor 3, TS (tidak setuju) skor 2, STS (sangat tidak setuju) skor 1. Berdasarkan hasil analisis angket, maka diperoleh skor terendah 24 dengan persentase minat $60 \%$ dan skor tertinggi 34 dengan persentase minat $85 \%$. Persentase rata-rata minat belajar siswa keseluruhan yaitu $73,33 \%$ dalam kategori baik. Hal ini menjelaskan bahwa siswa senang terhadap model Cooperative Script dengan media kartu gambar, dan mudah bagi mereka dalam memahami materi perkembangan model atom dengan adanya pelaksanaan pembelajaran dengan model dan media tersebut.

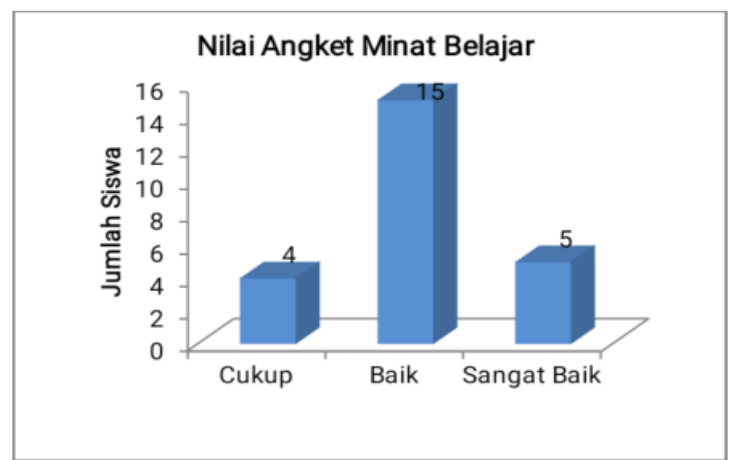

\section{Gambar 2. Diagram Nilai Angket Minat} Belajar Siswa

Minat belajar siswa yang diukur melalui pengisian angket yang dilakukan oleh seluruh siswa kelas X IPA 2 setelah 
proses pembelajaran menggunakan model Cooperative Script dengan media kartu gambar pada materi perkembangan model atom selesai. Setiap butir pernyataan yang berjumlah 10 sesuai dengan indikator minat belajar. Berdasarkan hasil penilaian, terdapat 4 orang siswa termasuk kategori cukup dikarenakan siswa memiliki sedikit kesulitan dalam mencocokkan pilihan jawaban dengan kartu gambar dan waktu yang terbatas saat melakukan presentasi. Selanjutnya, 15 orang siswa termasuk kategori baik dikarenakan siswa mampu bekerja sama dengan baik sesama kelompok berpasangan pada saat pengerjaan LKS, kartu gambar dan presentasi. Sedangkan 5 orang siswa termasuk kategori sangat baik dikarenakan siswa mampu bekerja sama dengan sangat baik sesama kelompok berpasangan pada saat pengerjaan LKS, kartu gambar dan presentasi.

Model Cooperative Script dengan media kartu gambar mampu membuat siswa tertarik dengan pembelajaran dikarenakan model tersebut memicu keaktifan siswa dalam bekerja sama mengerjakan soal di kartu gambar dan LKS. Rata-rata persentase minat belajar keseluruhan, yaitu 73,33\% dengan kategori baik. Berdasarkan jumlah masing-masing kriteria maka terlihat bahwa 20 siswa atau 83,33\% memberikan respon positif setelah dilaksanakannya proses pembelajaran dengan model Cooperative Script dengan media kartu gambar pada materi perkembangan model atom. Hal tersebut sesuai dengan pernyataan Winkel (dalam Kartini, 2007:1) bahwa minat dapat diartikan sebagai kecenderungan subyek yang menetap, untuk dapat merasa tertarik pada suatu bidang atau pokok bahasan tertentu dan merasa senang untuk mempelajari materi itu. Hasil ini menunjukkan bahwa model pembelajaran Cooperative Script dengan media kartu gambar berpengaruh terhadap minat belajar siswa.

\section{KESIMPULAN}

Berdasarkan hasil penelitian dapat disimpulkan bahwa model pembelajaran Cooperative Script dengan media kartu gambar mempengaruhi minat belajar siswa pada materi perkembangan model atom kelas X IPA SMA Negeri 1 Peusangan dengan persentase minat belajar $73,33 \%$ dan kategori baik. Model pembelajaran Cooperative Script dengan media kartu gambar mempengaruhi hasil belajar kognitif siswa pada materi perkembangan model atom kelas X IPA SMA Negeri 1 Peusangan dengan adanya perbedaan ratarata nilai pretest sebesar 35,63 dan rata-rata nilai posttest sebesar 78,33.

\section{SARAN}

Berdasarkan hasil penelitian, maka adapun saran yang dapat disampaikan adalah sebagai berikut. Bagi sekolah, dengan adanya pengaruh terhadap hasil belajar siswa melalui penggunaan model pembelajaran Cooperative Script dengan media kartu gambar, maka model dan media ini dapat dijadikan alternatif dalam pembelajaran di kelas. Bagi guru, agar pelaksanaan pembelajaran dengan menggunakan model pembelajaran Cooperative Script dengan media kartu gambar dapat berjalan dengan baik, maka perlu persiapan sebaik-baiknya terhadap RPP, LKS, soal-soal, dan perangkat pembelajaran lainnya yang akan digunakan. Bagi peneliti selanjutnya, model pembelajaran Cooperative Script dapat digunakan untuk mengukur variable lain atau digunakan pada materi yang lain dengan menyesuaikan media yang akan digunakan.

\section{DAFTAR PUSTAKA}

Aritonang, K. T. 2008. "Minat dan Motivasi dalam Meningkatkan Hasil Belajar Siswa". Jurnal Pendidikan Penabur. Volume 7, No. 10: 11-21.

Budiyanto, Agus Krisno. 2016. Sintaks 45 Metode Pembelajaran 


\section{dalam Student Centered Learning $\quad(S C L)$. Malang: Anggota APPTI.}

Fahni, Annisa. 2014. "Pengaruh Metode Scaffolding dan Kemampuan Numerik Terhadap Hasil Belajar Siswa Pada Materi Laju Reaksi di MAN 2 Banda Aceh". Skripsi. Banda Aceh: Universitas Islam Negeri.

Indrawati, Rina, dan Rokhmaniyah. 2016. "Penerapan Model Cooperative Script dengan Media Grafis dalam Peningkatan Motivasi dan Hasil Belajar IPS pada Siswa Kelas IV SDN 4 Bumirejo Tahun Ajaran 2015/2016". Kalam Cendikia, Volume 4, No. 4.1: 401-407.

Kartini, Tien. 2007. "Penggunaan Metode Role Playing untuk Meningkatkan Minat Siswa dalam Pembelajaran Pengetahuan Sosial di Kelas V SDN Cileunyi I Kecamatan Cileunyi Kabupaten Bandung. "Jurnal Pendidikan Dasar. Volume 8, No. 1: 1-5.

Saidah dan Winda. "Efektivitas Finger Painting untuk menurunkan Perilaku Temper Trantum pada Anak Prasekolah di Perumahan Podomoro RW.10 Kel. Mojoroto Kecamatam Sukorame tahun 2018". Prosiding Seminar Nasional Teknopreneur Universitas Pasir Pengaraian. Volume 1, No. 1:96-104.

Sandyasa, E. 2016. "Penerapan Media Kartu Gambar untuk Meningkatkan Motivasi dan Hasil Belajar Siswa dalam Pembelajaran Boga Dasar Kelas $X$ Tata Boga di SMK Negeri 3 Wonosari”. Skripsi. Yogyakarta: Universitas Negeri Yogyakarta. 